\title{
Performance evaluation of WLAN in enterprise WAN with real- time applications based on OPNET modeler
}

\author{
Mohammed G. Al-Hamiri ${ }^{1}$, Haider. J. Abd ${ }^{2}$, Hanaa M. Al Abboodi ${ }^{3}$ \\ ${ }^{1}$ Computer Center, University of Babylon, Iraq \\ ${ }^{2,3}$ Department of Electrical Engineering, University of Babylon, Iraq
}

\begin{tabular}{l}
\hline Article Info \\
\hline Article history: \\
Received May 25, 2020 \\
Revised Aug 23, 2020 \\
Accepted Aug 30, 2020 \\
\hline
\end{tabular}

Keywords:

Delay

Load

OPNET

QoS

Response time

\begin{abstract}
Wireless local area networks (WLAN) has been used recently due to their benefits which exhibits outstanding mobility with easier and faster configurations. The wireless local area network performance is much influenced by both network topology and hardware specifications and thus will impact the quality of service (QoS) parameters which are delay, load, and response time. This works estimated the performance of WLAN in enterprise WAN based on the OPNET modeler. Three scenarios have been suggested which are FDDI scenario, FDDI Hybrid Star scenario, and FDDI hybrid ring scenario involving web browsing (HTTP) and file transfer protocol (FTP). Hardware objects and software configurations kept the same for all proposed scenarios. Different types of links and topologies have been applied among WLAN subnets as well as the involved gateway has been changed to measure parameters of quality of services (QoS) for all scenarios used. The findings confirmed that the FDDI hybrid ring scenario presents better performance than the FDDI Hybrid Star Scenario and FDDI scenario in terms of WLAN delay, WLAN load, FTP download response time, and HTTP object response time.
\end{abstract}

This is an open access article under the CC BY-SA license.

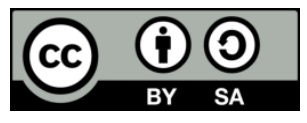

\section{Corresponding Author:}

Mohammed Ghadhban Al-Hamiri

Computer Center

University of Babylon

Hillah City, Babil Province, Iraq

m.ghadhban@uobabylon.edu.iq

\section{INTRODUCTION}

Wireless Local Area Networks (WLAN) have become necessary to operate many real-time applications such as web browsing HTTP, database, FTP, and video conference. These diversified real-time applications and development in WLAN networks increase Quality of service (QoS) challenges in terms of load, response time, traffic, and delay [1]. The WLAN performance is impacted by many factors which include topology, types of links, and qualifications of the software and hardware [2]. The performance of the network is also influenced by the calculation overhead and operation overload [3].

ITU-T standard E.800 states the required QoS which indicates consumer satisfaction about the service provider and their loyalty [4]. In other words, QoS is the requirements and rules that are followed to transfer information from the sender to the receiver [5]. There are two main parameters that determine the quality of service: qualitative parameters and quantitative parameters [6]. Qualitative parameters are the level of security, the flexibility of management. Quantitative parameters represent delay, load, and response time [7]. There is a significant challenge that is related to the Quality of Service (QoS) on the LAN networks. This challenge is represented by sharing the communication channel between consumers in an expected and 
measurable method [8]. Whenever traffic of video or voice involves the IP network, it has to share the media with FTP, database, and HTTP traffic [9, 10].

In communications, load represents the traffic that is conveyed by the network [11]. The load also refers to the proportion between the capacity of the channel and the traffic. Data in computer networks are usually transferred as packets, which cause the network load. When the load increases to higher rates, the network drops some of the packets because of the bounded capability in network links and nodes [12]. Topology with different types of links impacts on the balance of network load [13]. As mentioned, the rapid growth of real time applications results in serious challenges in terms of network delay and response time [14]. Response time is a measurement of time needed by a computer to meet the requirements of multimedia services such as web browsing HTTP and FTP file transferring [15].

On the other hand, the delay is a parameter that has a negative impact on WLAN networks [16]. Delay represents the time required to transfer information from sender to receiver. So, the delay must be processed accurately to meet the requirements of QoS. Delay challenges become more complicated because of the increased usage of WLAN networks. Real-time applications such as HTTP, FTP, and database access are influenced by delay $[17,18]$.

Delay is affected by the increased traffic that uses the whole bandwidth. The real-time applications are influenced by delay differently. For instance, the delay is significant for HTTP and database access. However, delay represents a serious challenge to voice and video conference applications [19, 20]. The QoS issues related with the IP terminal are the decision of codecs utilized in the terminal, the exhibition of the codec to different sorts of network corruption, the delays of signal process, the delays of call preparing, the delays related with security problems, and the sound delay in digital communication channel [21]. Simulation tools are developed to expect problems of network performance and to evaluate QoS [22]. To evaluate the performance of any WLAN networks in terms of Quality of Service (QoS) parameters, a modeler such as OPNET is required.

OPNET modeler is a virtual program for simulating, testing designs, and expecting the behavior of communication networks that involve network applications, data servers, and technologies [23, 24]. Simulating models become a common way to analyze the features and characteristics of suggested models in a wide range of research areas $[25,26]$. This modeler is a tool to predict the performance and behavior of communication and WLAN networks [27, 28]. Moreover, this modeler supports the creation of network topologies such as Star, and Ring topologies that are involved in this research. Also, this tool has the ability to simulate, run, and evaluate different scenarios, and compare their statistics such as delay, load, and response time [29]. Therefore, this simulation tool can help to choose an appropriate network design at a low cost. Thus, the cost, delay, and performance of each design in this simulation tool can be estimated [30-32]. The research goal is to evaluate the WLAN performance which will result in reducing general costs and improving the quality of service (QoS).

The rest of this paper is organized as follows: Section 2 presents the Research Method used in this paper. Section 3 states the OPNET simulation results. The Conclusion is given in Section 4.

\section{RESEARCH METHOD}

This research simulates WLAN with fixed LAN in enterprise WAN using the OPNET modeler. There are three proposed scenarios involved in this research which are called: FDDI, FDDI Hybrid Star, and FDDI Hybrid Ring. In this research, two comparisons in terms of WLAN delay, WLAN load, FTP and HTTP response time are conducted. The first comparison is done between the FDDI scenario and the FDDI Hybrid Star scenario, while the second comparison is achieved between the FDDI Hybrid Star scenario and the FDDI Hybrid Ring scenario. All proposed scenarios have the same objects, applications, profiles, services, and configurations. Application definitions in application configuration are set as default, and profile configurations are set as sample profiles. Additionally, firewalls are set to support all services, and servers have been created to support real-time applications which are web browsing (HTTP) and FTP applications.

Table 1 shows the number of involved objects in each scenario in this research. The difference between FDDI and FDDI Hybrid Star includes two things. The FDDI links between the FDDI gateway and each subnet in the FDDI scenario are replaced by 1000BaseX link in the FDDI Hybrid Star scenario. Also, the fddi lan (fddi16_switch_23) in each subnet in FDDI scenario is replaced with fddi lan (fddi16_switch_48) in FDDI Hybrid Star scenario. On the other hand, the difference between FDDI Hybrid Star and FDDI Hybrid Ring includes the connection among the subnets and the fddi gateway. In other words, the topology is ring among subnets in FDDI Hybrid Ring whereas the FDDI Hybrid Star has star topology among the same subnets. Figure 1, 2, and 3 show the design of FDDI scenario, FDDI Hybrid Star scenario, and FDDI Hybrid Ring scenario respectively. Subnet of each scenario can be seen in Figure 4. 
Table 1. Number of objects in each scenario

\begin{tabular}{|c|c|c|}
\hline Object & Model name & Quantity \\
\hline Internet backbone & Ip32_cloud & 1 \\
\hline firewall fddi & fddi2_slip8_firewall & 1 \\
\hline switch fddi & fddi16_switch_23 & 1 \\
\hline servers & fddi_server & 2 \\
\hline gateway fddi & fddi_slip8_gtwy_25 & 1 \\
\hline subnet $(0,1,2)$ & subnet & 3 \\
\hline fddi router & wlan_fddi2_tr2_router & 1 \\
\hline wlan-node $(0-4)$ & wlan workstations & 5 \\
\hline fddi lan & fddi16_switch_23 & 1 in FDDI scenario \\
\hline fddi lan & fddi16_switch_48 & 1 in each FDDI Hybrid (Star and Ring) \\
\hline node $(0-14)$ & fddi workstations & 45 \\
\hline FDDI links & FDDI & 11 in FDDI scenario, 8 in each FDDI Hybrid (Star and Ring) \\
\hline Gigabit links & 1000BaseX & 3 in FDDI Hybrid Star and 4 FDDI Hybrid Ring \\
\hline
\end{tabular}

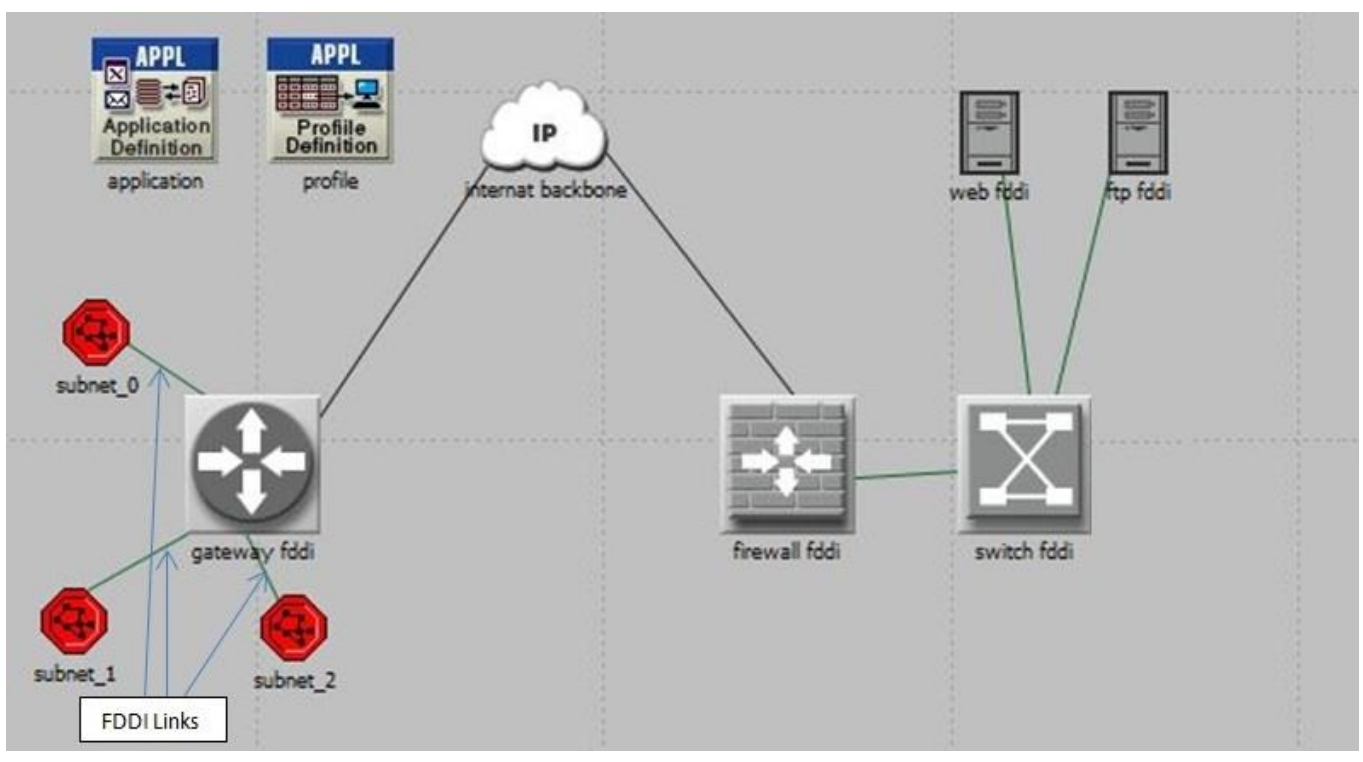

Figure 1. FDDI scenario (scenario 1)

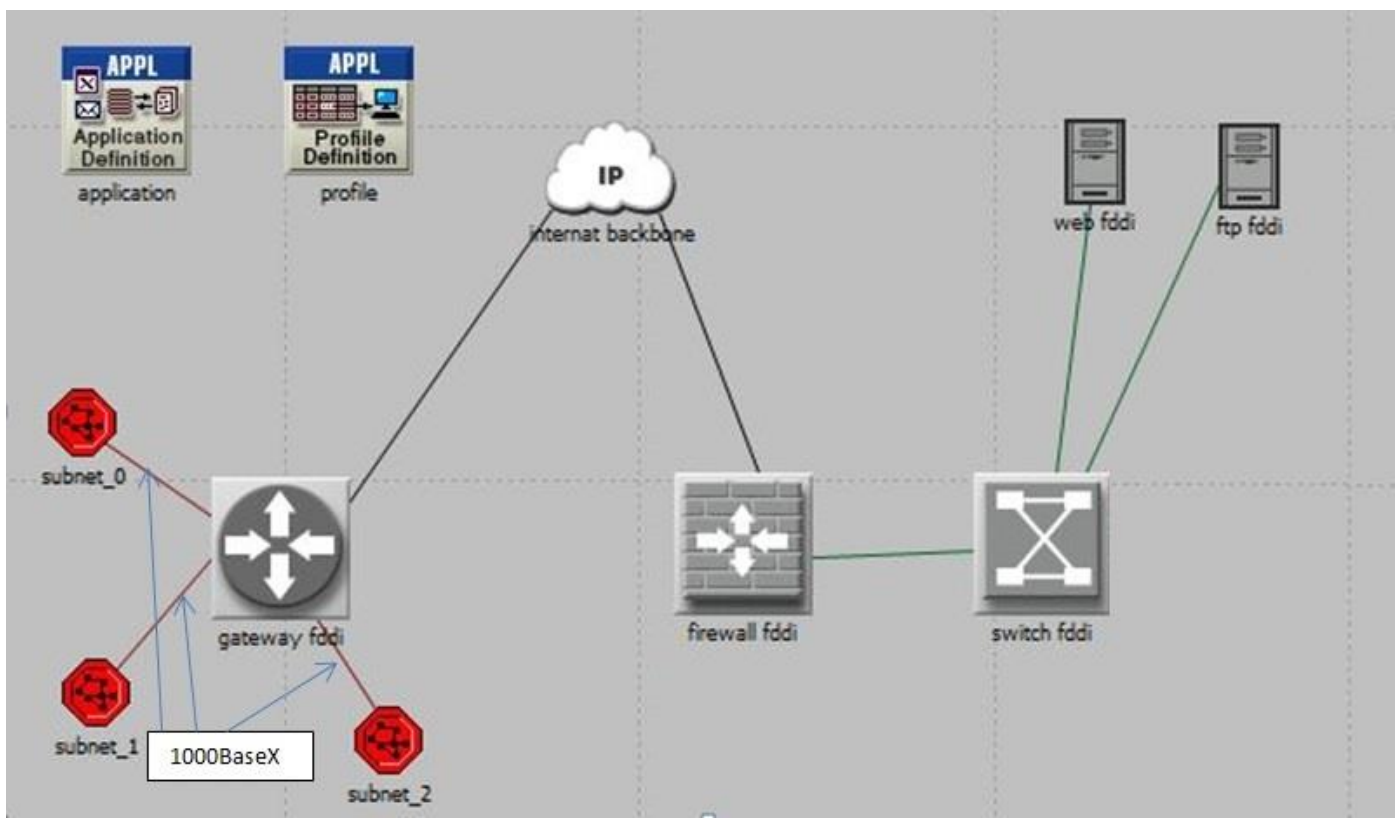

Figure 2. FDDI hybrid star scenario (scenario 2) 


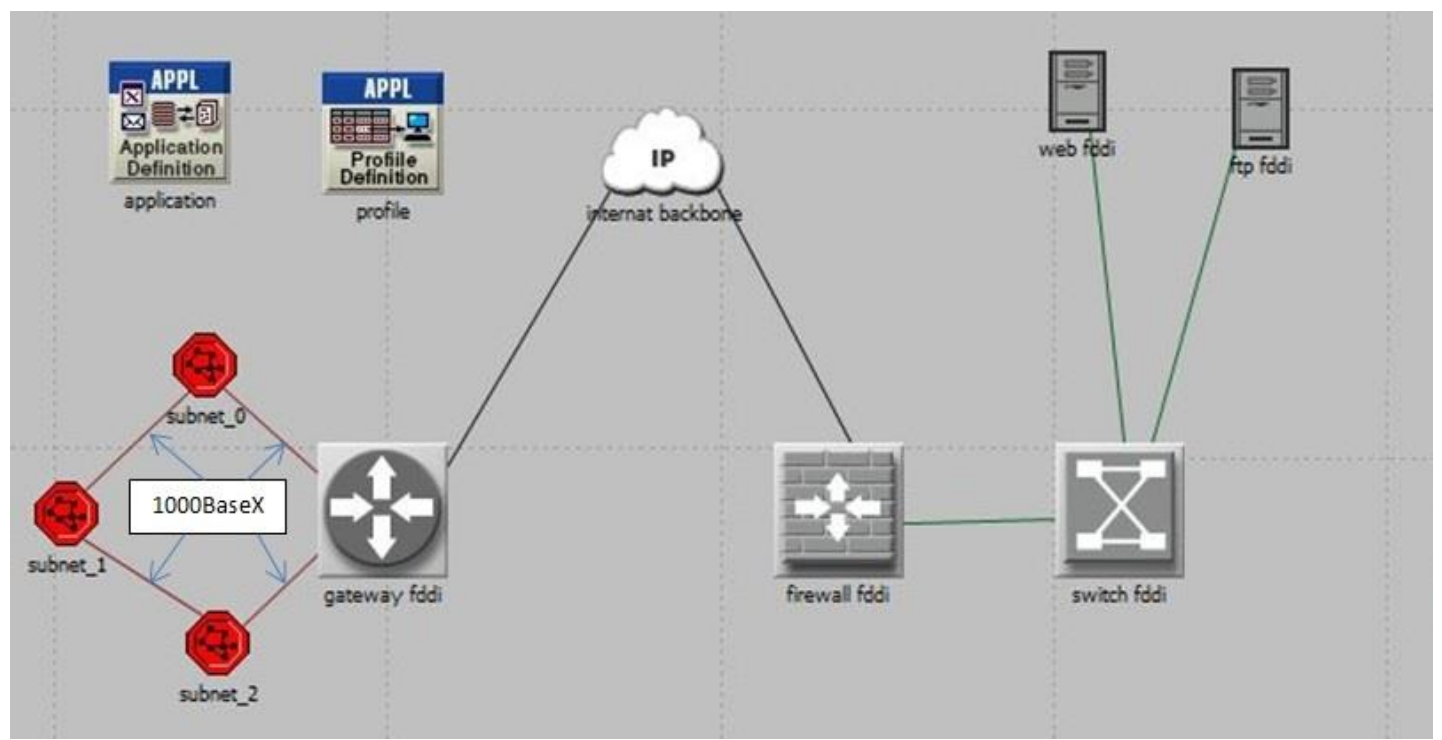

Figure 3. FDDI hybrid ring scenario (scenario 3)

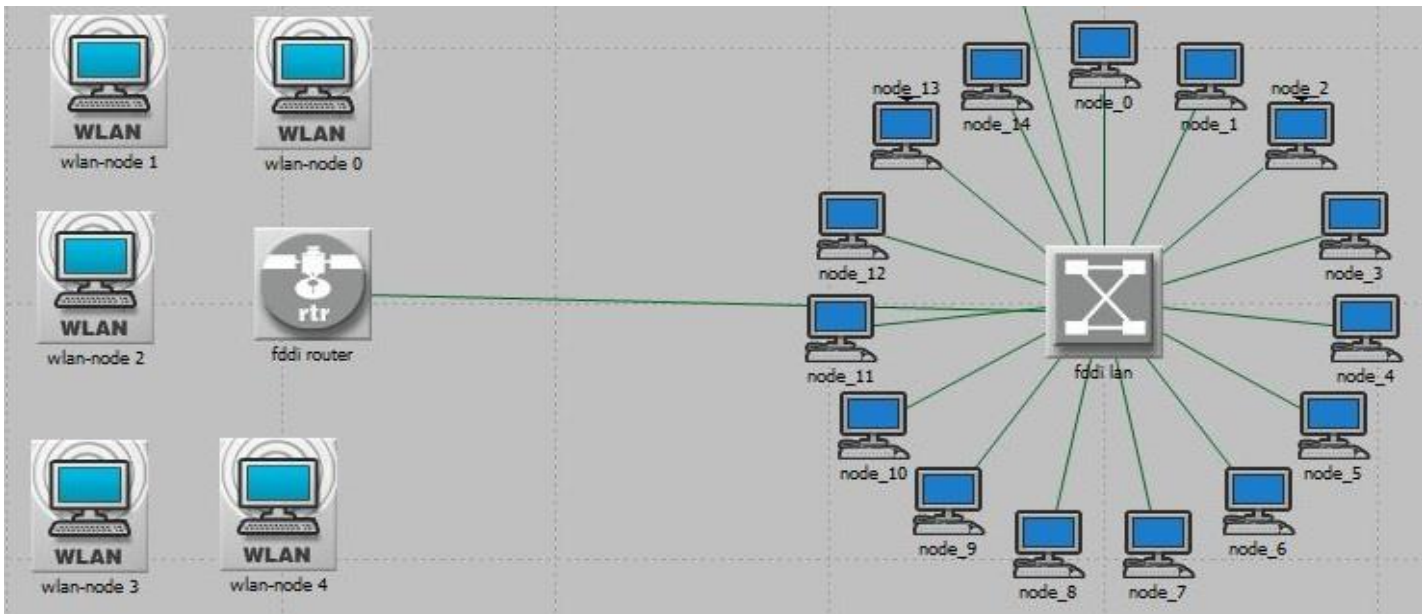

Figure 4. Subnet Connectivity in (senarios $1,2, \& 3)$

\section{OPNET SIMULATION RESULTS}

After completing the design, it has been run at a simulation time of twenty minutes. Results are collected for the three scenarios in terms of WLAN delay, WLAN load, FTP download response time, and HTTP object response time. Two comparisons have been achieved to evaluate three scenarios proposed in this research.

The first comparison is done between the FDDI scenario (scenario 1) and the FDDI Hybrid Star scenario (scenario 2). Figures 5 and 6 show the global statistics of WLAN delay and WLAN load respectively for the FDDI scenario and FDDI Hybrid Star scenario. The results state that WLAN delay and WLAN load of the FDDI Hybrid star scenario are less than WLAN delay and WLAN load of the FDDI scenario. This happens because of the replaced links between the fddi gateway and the subnets. FDDI link of FDDI scenario can transfer 100 megabits per second, whereas the 1000BaseX link in FDDI Hybrid Star can support 1 gigabit per second. Figures 7 and 8 present the global statistics of FTP download response time and HTTP object response time respectively. The results generally state that the FDDI Hybrid Star scenario has lower FTP download response time and HTTP object response time than the FDDI scenario. This encourages extending the research in the FDDI Hybrid Star which results in the FDDI Hybrid Ring scenario. 


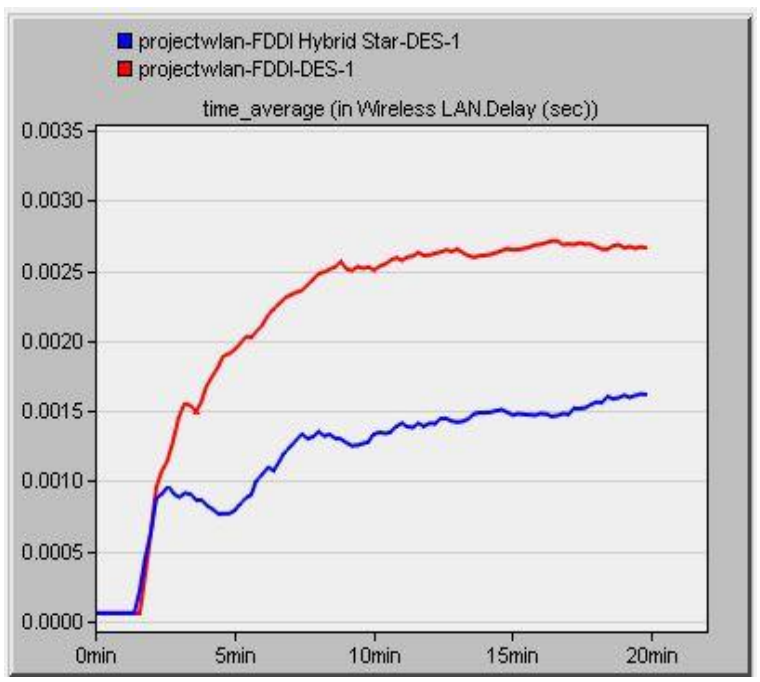

Figure 5. WLAN delay for (scenario $1 \& 2$ )

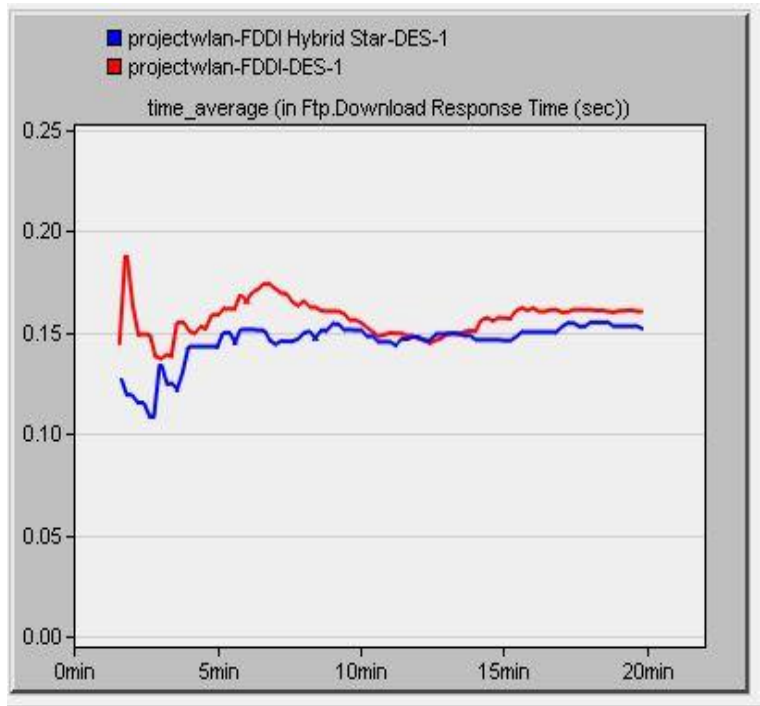

Figure 7. FTP download response time for (scenario $1 \& 2$ )

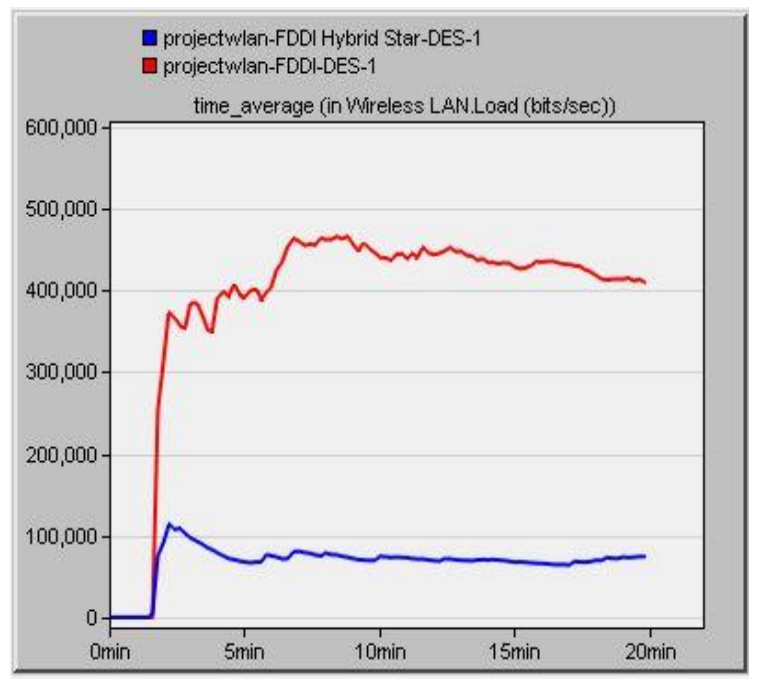

Figure 6. WLAN load for (scenario $1 \& 2$ )

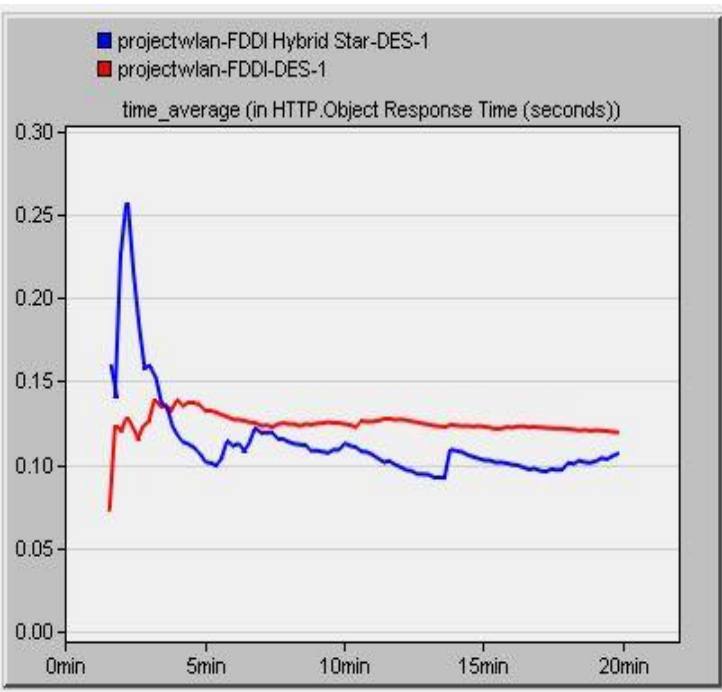

Figure 8. HTTP object response time for (scenario $1 \& 2$ )

The second comparison is done between the FDDI Hybrid Star scenario (scenario 2) and the FDDI Hybrid Ring scenario (scenario 3). Figures $9 \& 10$ show the global statistics of WLAN delay and WLAN load respectively, for FDDI Hybrid Star and FDDI Hybrid Ring. WLAN delay and WLAN load of FDDI Hybrid Ring are less than WLAN delay and WLAN load of FDDI Hybrid Star. This happens because each subnet in the FDDI Hybrid Ring scenario has an additional link which results in more flexibility in traffic routing. So, when there is a load in a link, traffics can be redirected to the other link.

The global statistics of FTP download response time and HTTP object response time for the FDDI Hybrid Star scenario and FDDI Hybrid Ring scenario are displayed in Figures 11 and 12. Results state that the FDDI Hybrid Ring scenario has lower FTP download response time and HTTP object response time than the FDDI Hybrid Star scenario. These results show the effect of Ring topology and gigabit links in improving performance parameters in terms of WLAN delay, WLAN load, FTP download response time, and HTTP object response time. Therefore, this improvement positively affects the Quality of Service (QoS) and performance of the WLAN networks. 


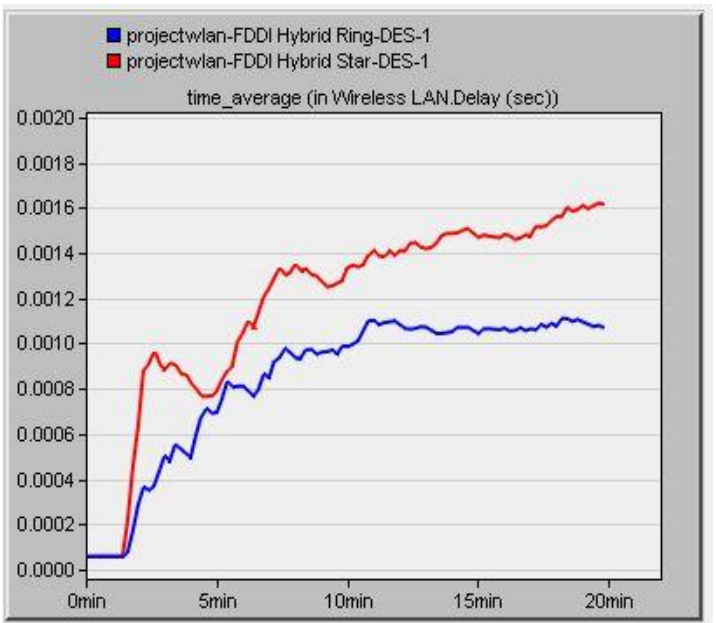

Figure 9. WLAN delay for (scenario $2 \& 3$ )

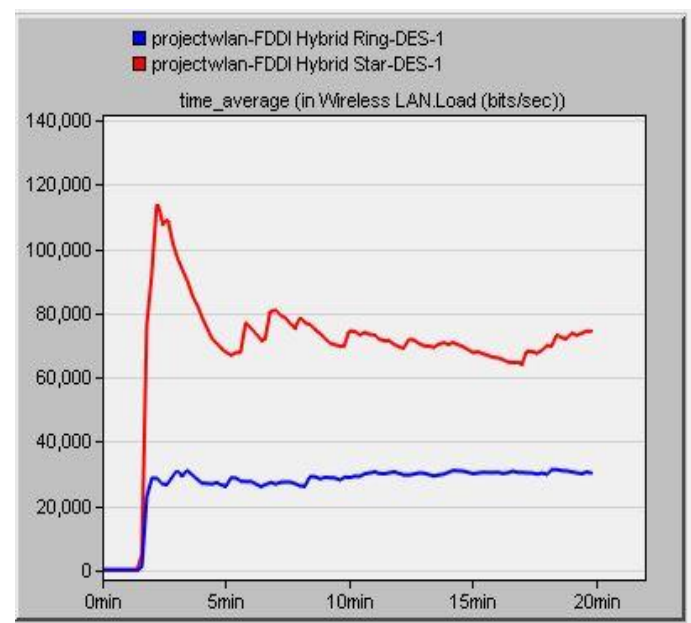

Figure 10. WLAN load for (scenario $2 \& 3$ )

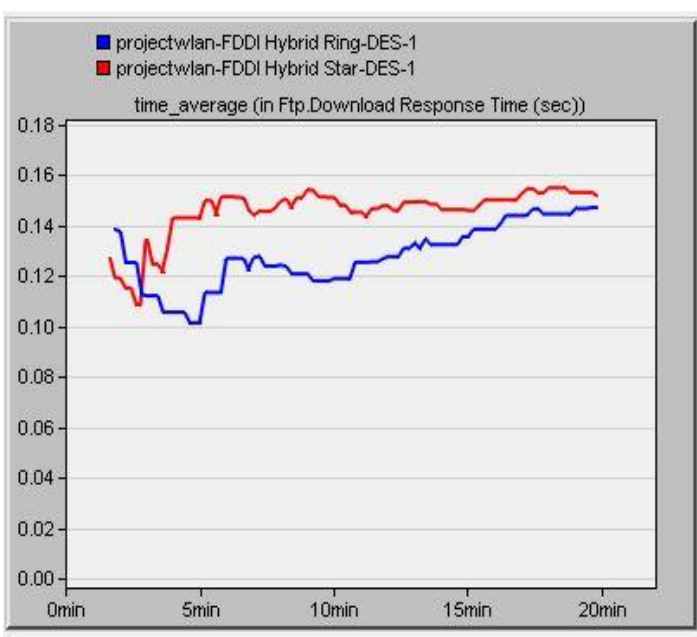

Figure 11. FTP download response time for (scenario $2 \& 3$ )

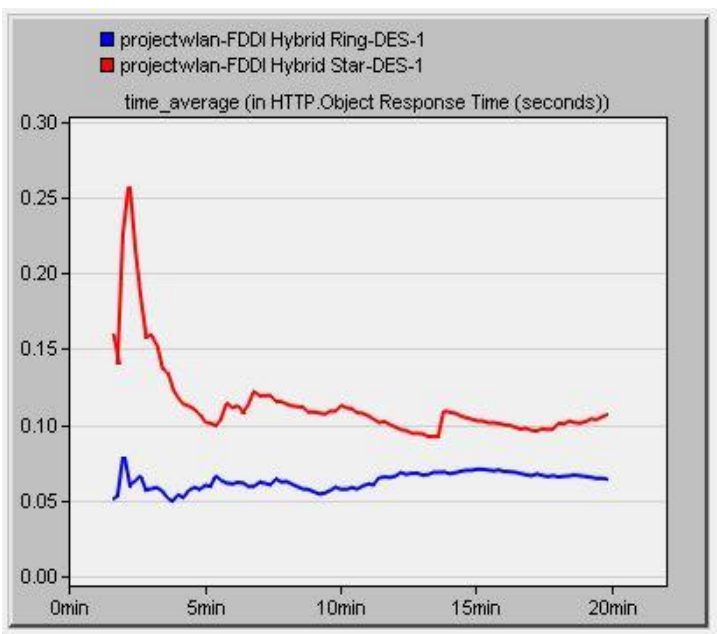

Figure 12. HTTP object response time for (scenario $2 \& 3$ )

\section{CONCLUSION}

This research measures the performance of WLAN in enterprise WAN using OPNET software. FDDI scenario, FDDI Hybrid Star scenario, and FDDI Hybrid Ring scenario are three scenarios suggested in this paper. All suggested scenarios have the same objects, applications, profiles, services, and configurations. These scenarios involve gateway, firewall, and servers of real-time applications in terms of web browsing (HTTP) and FTP servers. The difference among scenarios includes links between WLAN subnets and fddi gateways which are FDDI links and 1000BaseX links. In addition, the difference involves the topology that connects these subnets in terms of Star and Ring topology. Two comparisons have been achieved among the three scenarios. The results of comparisons stated that the FDDI Hypred Ring scenario has better performance than the FDDI Hybrid Star Scenario and FDDI scenario in terms of WLAN delay, WLAN load, FTP download response time, and HTTP object response time. Also, FDDI Hybrid Star achieves better performance than the FDDI scenario in terms of the same QoS parameters.

\section{REFERENCES}

[1] T. Zaidi and N. N. Dwivedi, "Performance of Step Network Using Simulation Tool," International Journal of Computer Science and Information Security, vol. 14, no. 10, 2017.

[2] F. P. Tso, S. Jouet, and D. P. Pezaros, "Network and server resource management strategies for data centre infrastructures: A survey," Computer Networks, vol. 106, pp. 209-225, 2016. 
[3] P. C. Newton, E. G. D. P. Raj, L. Arockiam and R. H. Prasath, "NPASA: A Noble Path Selection Algorithm", International Symposium on Computer Science and its Applications, Hobart, ACT, pp. 52-55, 2008.

[4] A. Čolaković and H. Bajrić, "Assessing customer satisfaction based on QoS parameters," International Journal for Quality Research, vol. 11, no. 1, pp. 221-240, 2017.

[5] P. Newton and L. Arockiam, "A Quality of Service Performance Evaluation Strategy for Delay Classes in General Packet Radio Service”, International Journal of Advanced Science and Technology, vol. 50, pp. 91-98, 2013.

[6] W. Kellerer, A. Basta, and A. Blenk, "Flexibility of Networks: a new measure for network design space analysis," Networking and Internet Architecture, 2015.

[7] V. Aleksieva, "The system of qualitative and quantitative indicators for MPLS networks analysis," International Conference on Computer Systems and Technologies - CompSysTech 10, pp. 269-274, 2010.

[8] P. Zhou and O. Yang, "Scalability and QoS guarantee in IP networks," Proceedings Eight International Conference on Computer Communications and Networks (Cat. No.99EX370), pp. 427-433, 1999.

[9] M. Valino, J. Corchado, "VoIP: the convergence of networks", Computing and Imformation Systems, vol. 6, no 3, pp. 105-112, 1999.

[10] P.P. White, "ATM switching and IP routing integration: The next stage in internet evolution", IEEE Communication Magazine, pp. 78-83, 1998.

[11] K. Xiong, S. Leng, J. Hu, X. Chen, and K. Yang, "Smart network slicing for vehicular Fog-RANs," IEEE Transactions on Vehicular Technology, vol. 68, no. 4, pp. 3075-3085, 2019.

[12] A. Y. Ardiansyah and R. Sarno, "Performance analysis of wireless sensor network with load balancing for data transmission using xbee zb module," Indonesian Journal of Electrical Engineering and Computer Science, vol. 18, no. 1 , pp. 88-100, 2020.

[13] S. H. Mohammed and A. D. Jasim, "Evaluation of firewall and load balance in fat-tree topology based on floodlight controller," Indonesian Journal of Electrical Engineering and Computer Science, vol. 17, no. 3, pp. 1157-1164, 2020.

[14] Liu, L., Chen, C., Pei, Q., Maharjan, S. and Zhang, Y., "Vehicular edge computing and networking: A survey," Mobile Networks and Applications, 2020.

[15] L. P. Jie, R. Ramlan, R. Hassan, R. Omar, and C. S. Wei, "Website quality of MalaysianTechnical University," Indonesian Journal of Electrical Engineering and Computer Science, vol. 18, no. 3, pp. 1624-1628, 2020.

[16] J. Holub, M. Kastner, and O. Tomiska, "Delay effect on conversational quality in telecommunication networks: Do we mind?," 2007 Wireless Telecommunications Symposium, Pomona, CA, pp. 1-4, 2007.

[17] L. D. Dhomeja, et al, "Performance Analysis of WLAN Standards for Video Conferencing Applications," International Journal of Wireless \& Mobile Networks, vol. 3, no. 6, pp. 59-69, 2011.

[18] B. Goodman, "Internet telephony and modem delay," IEEE Network, vol. 13, no. 3, pp. 8-16, 1999.

[19] A. Khalifeh, A. El-Mousa, and A. Shaout, "A Telemedicine Video Conferencing System: Implementation Challenges and Solutions," the proceedings of the International Conference on Information and Communication Systems, At Amman, Jordan, 2009.

[20] T. Aziz, M. Islam, H. Karim, and A. Popescu, "Effect of packet delay variation on video/voice over diffserv-Mpls In Ipv4/Ipv6 networks," International Journal of Distributed and Parallel systems, vol. 3, no. 1, pp. 27-47, 2012.

[21] A.M. Grilo, P.M. Carvalho, L.M. Medeiros, M.S. Nunes, "VTOA/VoIP/ISDN Telephony Gateway", 2nd International Conference on ATM, ICATM'99, Colmar, pp. 203-235, 1999.

[22] G. Armitage, "MPLS: the magic behind the myths", IEEE Communications Magazine, vol. 38, no 1, pp. 124-131, 2000.

[23] M. Al- Rudaini, K. Obood, "Wireless network simulation using OPNET IT guru academic edition", Technical Report, Feb 2009.

[24] S. A.-S. Lafta, A. H. Ali, M. M. Kareem, Y. A. Hussein, and A. H. Ali, "Performance simulation of broadband multimedia wireless networks simulation based on OPNET," Indonesian Journal of Electrical Engineering and Computer Science, vol. 17, no. 1, pp. 1-9, 2020.

[25] S. Mittal, et al., "Design Exploration and Implementation of Simplex Algorithm over reconfigurable computing platforms," IEEE International Conference on Digital Convergence, pp. 204-209, 2011.

[26] S. Gupta et el., "Guaranteed QoS with MIMO Systems for scalable low motion video streaming over scarce resource wireless channels," Proceedings of Second International Conference on Information Processing, I.K. International Pvt Ltd, pp. 452-466, 2008.

[27] S. W. Barasa, S. M. Mbugua, and S. M. Karume, "Map of the various configuration attributes from IPv4 to IPv6 networks for dual stack, 6to4 tunnelling and NAT: Modelling designs in OPNET modeller," International Journal of Computer Science and Mobile Computing, vol. 7, no. 7, pp. 32-44, 2018.

[28] A. A. Abdulrazzaq, A. J. Abid, and A. H. Ali, "QoS performances evaluation for mobile WIMAX networks based on OPNET," International Journal of Applied Engineering Research, vol. 13, no. 9, pp. 6545-6550, 2018.

[29] A. O. Barznji, et al, "TCP Performance Monitoring for Simulated Wired University Computer Network Using OPNET, " UKH Journal of Science and Engineering, vol. 3, no 1, pp. 18-28, 2019.

[30] A. Barznji, T. Rashid, and N. Al-Salihi, "Computer network simulation of firewall and VoIP performance monitoring," International Journal of Online and Biomedical Engineering, vol. 14, no. 9, pp. 4-18, 2018.

[31] M. Chen, Y. Miao, and I. Humar, "Large Sensor Network OPNET Model Debugging," OPNET IoT Simulation, pp. 249-294, 2019.

[32] S. Rhaif, A. Abdulrazzaq, R. Abdulnabi, and A. Ali, "Fiber optics based schemes modeling and simulation of QoS for Wi-Fi scenarios using OPNET modeler," International Journal of Electrical and Computer Engineering, vol. 10 , no. 3, pp. 2569-2578, 2020. 


\section{BIOGRAPHIES OF AUTHORS}

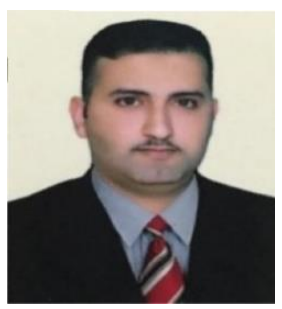

Mohammed G. Al-Hamiri earned his M.sc in the field of Telecommunication Engineering from Rochester Institute of Technology, NY, USA, 2017. He has more than three years of experience in teaching. He completed his BSc in Telecommunication Engineering, Al-Furat Al-Awsat Technical University, Najaf, Iraq, 2010. His research interests include symbol synchronization, satellite communication, wavelet transform, optical fiber communication, and digital signal processing.

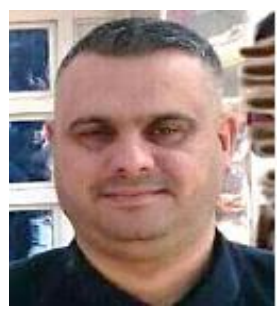

Dr. Haider J. Abd earned his Ph.D. in the field of Electrical Engineering from University of Tenaga Nasional, Malaysia, 2014. He has more than ten years of experience in teaching. He completed his MSc, in Electrical Engineering, University of Baghdad, Baghdad, Iraq, 2005. His research interests include optical fiber communication, Wireless communication, Digital signal processing, smart systems, Biomedical Engineering, Maglev system, and the Adaptive control system.

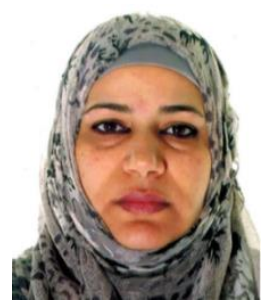

Dr. Hanaa M. Al Abboodi earned her Ph.D. in the field of Information Technology from the University of Salford Manchester. The United Kingdom, 2019. She has more than ten years of experience in teaching. She finished her MSc, in computer science, University of Information Technology and Communication, Baghdad, Iraq, 2005. Her research interests include machine learning, deep neural network, spiking neural networks, binaural hearing, digital signal processing, biomedical engineering, image processing, robotic engineering, and smart system. 